\title{
Second-Order Olfactory-Mediated Fear-Potentiated Startle
}

\author{
Gayla Y. Paschall ${ }^{1}$ and Michael Davis \\ Department of Psychiatry and Behavioral Sciences, Emory University School of Medicine, Atlanta, Georgia, 30322, USA
}

\begin{abstract}
Recently, we reported that discrete (4-sec) olfactory cues paired with footshock serve as effective conditioned stimuli (CSs) for potentiating the acoustic startle response in rats using the fear-potentiated startle paradigm. Because odors are such salient cues for the rat, and because of the robust olfactory conditioning observed previously, the current studies investigated second-order fear conditioning using olfactory and visual cues. In Experiments 1 and 2, we used a small number of first-order and second-order training trials on separate days to investigate second-order fear-potentiated startle. Significant potentiated startle was observed in animals receiving Paired/Paired training in both studies, but surprisingly, control animals in the Unpaired/Paired group (Exp. 1) also showed significant potentiated startle to a light S2 at testing. These findings are addressed in the Discussion. Overall, the results of both experiments suggest that olfactory cues serve as efficient S1 and S2 stimuli in second-order fear-potentiated startle paradigms when only a small number of first and second-order training trials are presented.
\end{abstract}

Recently, we reported that discrete (4-sec) olfactory cues paired with footshock serve as effective conditioned stimuli (CSs) for potentiating the acoustic startle response in rats using the fear-potentiated startle paradigm (Paschall and Davis 2002). In those studies, amyl acetate (5\%) had no significant effect on startle in untrained rats, but potentiated startle in animals receiving 1, 2, 5, or 10 odor-shock pairings. Olfactory-mediated fear-potentiated startle decreased, but was still significant up to $40 \mathrm{~d}$ after conditioning, and could be measured using test trials separated by as little as $30 \mathrm{sec}$. Those studies confirmed a previous report by Richardson et al. (1999), showing that ambient odors are also effective CSs for potentiating the startle response. Because odors are such salient cues for the rat, and because of the robust olfactory conditioning observed previously, the current studies investigated second-order olfactory fear conditioning.

Pavlov (1927) proposed that once a stimulus has been conditioned, it can serve the role of an unconditioned stimulus (US). In first-order Pavlovian conditioning, a previously neutral stimulus (i.e., a light), is paired with a biologically significant US that can be either aversive (i.e., footshock) or rewarding (i.e., food). The animal learns an association between the CS and the US, and later exhibits a conditioned response (CR) to that stimulus in the absence of the US. Conditioning of a second neutral stimulus (S2) with the previously conditioned (and now excitatory) firstorder stimulus (S1) is known as higher-order (or secondorder) conditioning. When later tested with S2, the animal

${ }^{1}$ Corresponding author.

E-MAIL gpaschall@aol.com; FAX (404) 727-3233.

Article and publication are at http://www.learnmem.org/cgi/doi/ $10.1101 / \mathrm{lm} .50602$. exhibits a CR, although S2 was never paired directly with the US.

The existence of second-order conditioning is important, as it increases the range of situations in which classical conditioning occurs, even without a primary unconditioned stimulus (cf. Domjan 1998). Because the motivational value of both the first and second-order stimuli are acquired rather than innate (as is the motivational value of the US), second-order conditioning techniques may help reveal the neural mechanisms that underlie the acquisition, expression, and representation of fear memories (for review, see Gewirtz and Davis 1998).

Olfactory-mediated fear-potentiated startle is such a robust effect that even a single-training trial can support learning (Paschall and Davis 2002). Therefore, in the current studies, we used a small number of first-order and secondorder training trials on separate days to investigate secondorder olfactory-mediated fear-potentiated startle.

\section{Experiment 1}

Typically, in second-order conditioning paradigms there are two phases, the first-order phase in which a neutral CS (S1) is paired with the US, and a second-order phase, in which a second neutral stimulus (S2) is paired with S1. In the second-order phase, S1 acts as a US by virtue of its association with the US during the first-order conditioning phase. When the animal is later tested with $\mathrm{S} 2$, a conditioned response similar to that exhibited previously to $\mathrm{S} 1$ is observed to S2. That is, S2 acquires associative strength to S1, even though it has never been paired directly with the US.

To assess the integrity of second-order conditioning, at least two control groups are needed for comparison. One control is to unpair S1 and the US during Phase 1 (the first-order phase). The lack of temporal contiguity between

LEARNING \& MEMORY 9:395-401 @ 2002 by Cold Spring Harbor Laboratory Press ISSN1072-0502/02 \$5.00

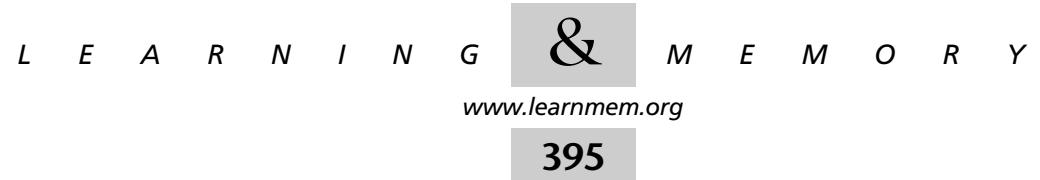


S1 and the US during first-order conditioning should disrupt learning to S1, and thereby make the S1-S2 association in Phase 2 (the second-order phase) weak or nonexistent. A second control is to unpair S1 and S2 in Phase 2. Again, a lack of temporal contiguity between the neutral S2 and the conditioned S1 should result in no learning to S1 by S2.

This study investigated second-order conditioning using an odor CS as S1 and a light CS as S2. In addition to the two control groups described above, three other control groups were added to the current study, an unpaired group that received unpaired odor-shock presentations in Phase 1 and unpaired light-odor presentations in Phase 2, a group that received no Phase 1 training and paired light-odor presentations in Phase 2, and a group that received no Phase 1 training and unpaired light-odor presentations in Phase 2. It was predicted that only the animals receiving paired odorshock training in Phase 1, and paired light-odor conditioning in Phase 2 would exhibit significant second-order conditioning relative to the control groups.

\section{Matching}

Forty-six rats were matched into six groups as follows: Paired/Paired (PRD/PRD; $n=7$ ), Paired/Unpaired (PRD/ UNP; $n=8$ ), Unpaired/Paired (UNP/PRD; $n=8$ ), Unpaired/ Unpaired (UNP/UNP; $n=7$ ), No/Paired (N/PRD; $n=8$ ), and No/Unpaired (N/UNP; $n=8$ ).

\section{Training}

All animals received $1 \mathrm{~d}$ of Phase 1 (first-order) and $1 \mathrm{~d}$ of Phase 2 (second-order) conditioning. For Phase 1, animals received either five paired (PRD/PRD and PRD/UNP groups) or five unpaired (UNP/PRD and UNP/UNP groups) odor-shock presentations. Paired training consisted of five, 4 -sec presentations of a 5\% amyl acetate odor CS that coterminated with 0.5 -sec footshock $(0.4 \mathrm{~mA}$; 4 -min intertrial interval-ITI). For the unpaired groups, animals received five unpaired odor-shock presentations, in which the odor CS was presented for $4 \mathrm{sec}$, followed $2 \mathrm{~min}$ later by a 0.5 -sec footshock (0.4mA). The N/PRD and N/UNP groups did not receive first-order training.

Phase 2 training was conducted $24 \mathrm{~h}$ after Phase 1 . For Phase 2, animals in the PRD/PRD, UNP/PRD, and N/PRD groups received five paired presentations of an 8-sec light CS that coterminated with the 4 -sec odor CS (4-min ITI). The PRD/UNP, UNP/UNP, and N/UNP groups received five unpaired presentations of an 8-sec light, followed 2 min later by the 4-sec odor CS.

\section{Testing}

All animals were tested with the light CS $48 \mathrm{~h}$ following Phase 2 conditioning. For testing, the animals were placed individually into the two test cages within the chamber. Following a 5-min acclimation period, animals were presented with 30 95-dB startle stimuli (Noise-Alone trials) at a 30-sec inter-stimulus interval (ISI). Thirty seconds after the last Noise-Alone trial, they were presented with the first of 10 light + startle stimulus trials (Light-Noise trials). On these test trials, the light was presented for $4 \mathrm{sec}$, and then the 50-msec startle stimulus was delivered $3.5 \mathrm{sec}$ after the onset of the light. After each Light-Noise trial, three NoiseAlone trials were presented at a $30-\mathrm{sec}$ ISI, so that NoiseAlone trials occurred 30, 60, and $90 \mathrm{sec}$ after each light.

\section{RESULTS}

Figure 1 shows the percent potentiated startle to the light in each of the six groups. Table 1 shows mean startle amplitude on the noise-alone and light-noise trials, and the difference between the two, in each of the six groups. Because we have found that percent potentiated startle rather than the absolute difference score is a better metric to assess fear-potentiated startle (Walker and Davis 2002), the data were analyzed using percent-potentiated startle. A one-way ANOVA performed on the percent change scores found a significant group effect, $F(5,40)=4.05, P<.01$. Single sample t-tests found significant potentiated startle in the presence of the light CS in both the PRD/PRD, $t(7)=2.79$, $P<.05$, and the UNP/PRD, $t(8)=3.47, P<.01$ groups. Post hoc Fishers LSD analyses found that the PRD/PRD group showed significant potentiated startle to the light CS relative to the PRD/UNP, UNP/UNP, N/PRD, and N/UNP groups

Second-Order Conditioning - Light Test

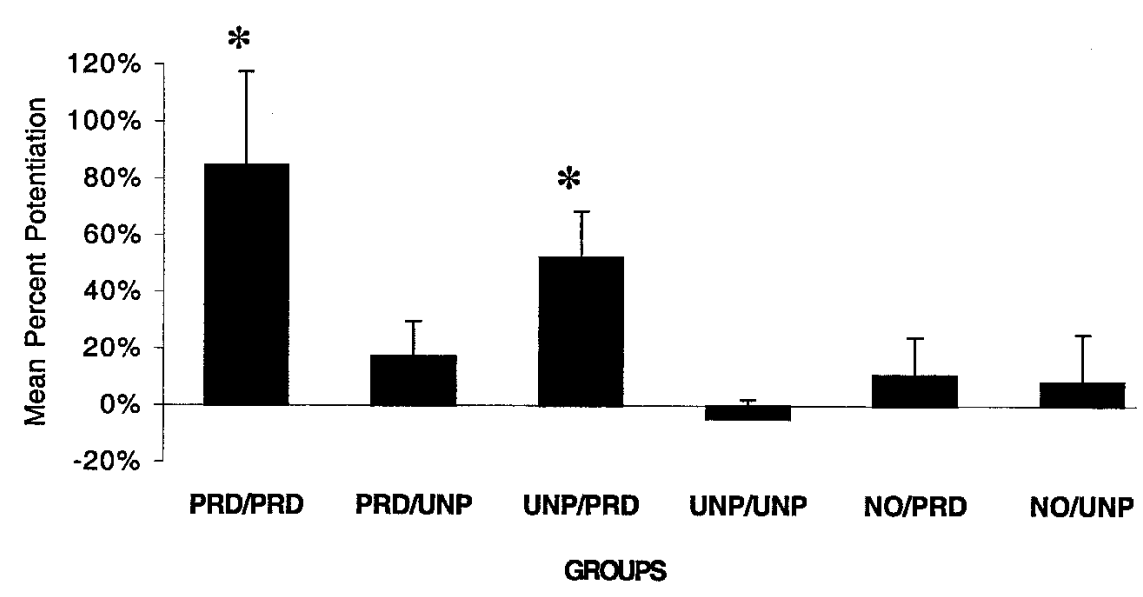

Figure 1 Mean $( \pm$ SEM) percent potentiation [(Light-noise trials minus Noise-Alone trials) $\div$ Noise-Alone $\times 100$ ] following second-order conditioning using an odor as S1 and a light as S2. Asterisks denote significant potentiation to S2 in the Paired/Paired (PRD/PRD) and Unpaired/ Paired (UNP/PRD) groups $(P<.05)$.

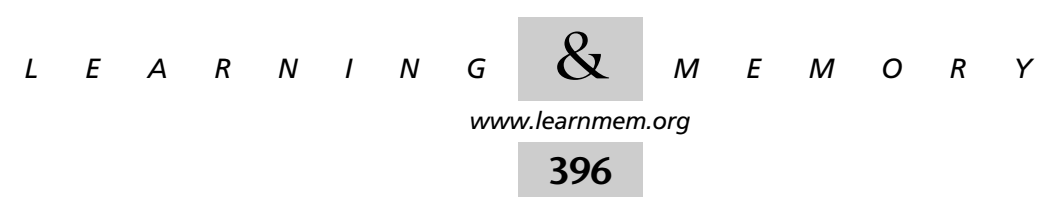


Table 1. Derivation of Difference Scores: Mean CS-Noise Trials Minus Mean Combined Noise-Alone (NA) Trials

\begin{tabular}{|c|c|c|c|c|c|c|}
\hline \multicolumn{7}{|c|}{ Experiment 1} \\
\hline Groups & PRD/PRD & PRD/UNP & UNP/PRD & UNP/UNP & N/PRD & N/UNP \\
\hline Combined NA Trials & 269.79 & 293.99 & 271.11 & 284.57 & 171.93 & 146.54 \\
\hline Light-Noise Trials & 513.70 & 325.17 & 395.72 & 280.67 & 195.95 & 164.75 \\
\hline Difference & 243.91 & 31.18 & 124.61 & -3.90 & 24.03 & 18.21 \\
\hline \multicolumn{7}{|c|}{ Experiment 2} \\
\hline Groups & PRD/PRD & PRD/UNP & UNP/PRD & & & \\
\hline Combined NA Trials & 237.40 & 343.83 & 315.77 & & & \\
\hline Odor-Noise Trials & 330.17 & 384.20 & 299.89 & & & \\
\hline Difference & 92.77 & 40.37 & -15.87 & & & \\
\hline
\end{tabular}

(all $P$ 's $<.05)$. There was no significant difference between the PRD/PRD and the UNP/PRD groups, $P>.05$.

These results show that an odor CS can support second-order conditioning, as the PRD/PRD group showed significant potentiated startle to the light CS relative to all but one of the control groups. That the PRD/PRD and UNP/PRD groups did not significantly differ was rather surprising, and these results will be addressed in the Discussion.

\section{Experiment 2}

This study was a replication of Experiment 1, but used a light CS as S1 and a 5\% amyl acetate odor CS as S2.

\section{Matching}

Twenty-four animals were matched into three groups of eight rats each as follows: Paired/Paired (PRD/PRD), Paired/ Unpaired (PRD/UNP), and Unpaired/Paired (UNP/PRD).

\section{Training}

All animals received $1 \mathrm{~d}$ of Phase 1 (first-order) and $1 \mathrm{~d}$ of Phase 2 (second-order) conditioning. For Phase 1, animals received either five paired ( $\mathrm{PRD} /$ PRD and PRD/UNP groups) or five unpaired (UNP/PRD group) lightshock presentations. Paired training consisted of five, 4 -sec presentations of a light CS that coterminated with 0.5 -sec footshock $(0.4 \mathrm{~mA}$; 4-min ITI). For the unpaired groups, animals received five unpaired lightshock presentations, in which the light CS was presented for $4 \mathrm{sec}$, followed 2 min later by a 0.5 -sec footshock $(0.4 \mathrm{~mA})$.

Phase 2 training occurred $24 \mathrm{~h}$ after Phase 1. In Phase 2, animals in the PRD/PRD and UNP/PRD groups received five paired presentations of an 8 -sec 5\% amyl acetate odor CS that coterminated with the 4 -sec light CS (4-min ITI). The PRD/UNP $(P<.05)$. group received five unpaired presentations of the 8-sec odor, followed $2 \mathrm{~min}$ later by the 4-sec light CS.

\section{Testing}

All animals were tested with the odor CS $48 \mathrm{~h}$ following Phase 2 conditioning. For testing, the animals were placed individually into the two test cages within the chamber. Following a 5-min acclimation period, they were presented with 30 95-dB startle stimuli (Noise-Alone trials) at a 30-sec ISI. Throughout the test, a continuous flow of filtered clean air $(2.00 \mathrm{~L} / \mathrm{min})$ was delivered into the chamber. Thirty seconds after the last Noise-Alone trial, the animals were presented with the first of 10 odor + startle stimulus trials (Odor-Noise trials). On these test trials, the Odor 1 solenoid was opened for $4 \mathrm{sec}$, and the 50-msec startle stimulus was delivered $3.5 \mathrm{sec}$ after the solenoid was opened. After each Odor-Noise trial, three Noise-Alone trials were presented at a 30-sec ISI, so that Noise-Alone trials occurred 30, 60, and $90 \mathrm{sec}$ after each odor.

Figure 2 shows the mean percent potentiated startle

\section{Second-Order Conditioning - Odor Test}

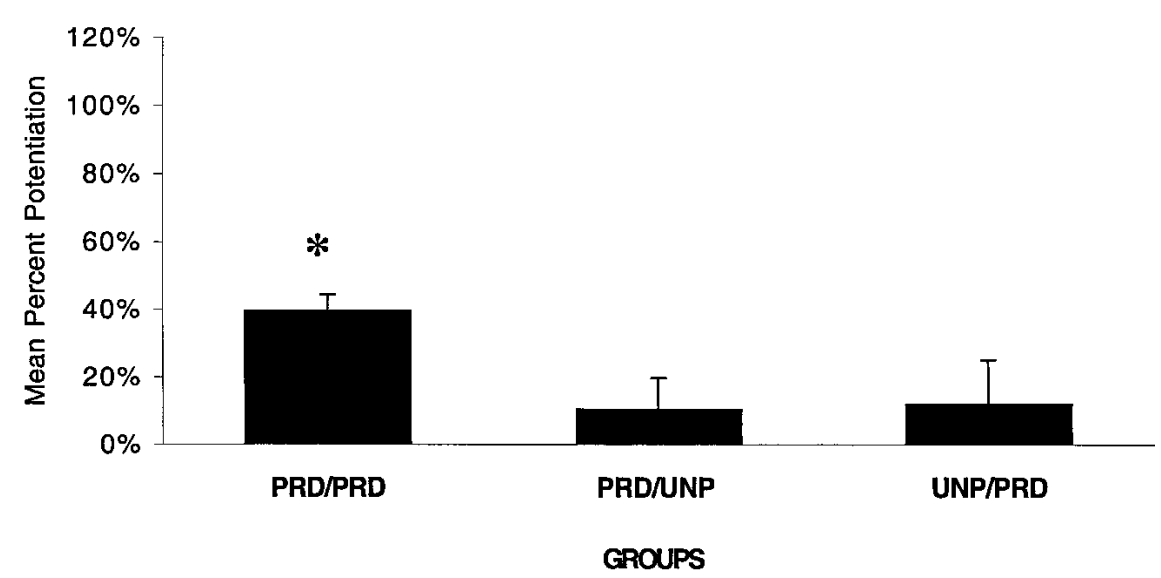

Figure 2 Mean $( \pm$ SEM) percent potentiation [(Odor-noise trials minus Noise-Alone trials $) \div$ Noise-Alone $\times 100$ ] following second-order conditioning using a light as S1 and an odor as S2. Asterisks denote significant potentiation to S2 only in the Paired/Paired (PRD/PRD) group

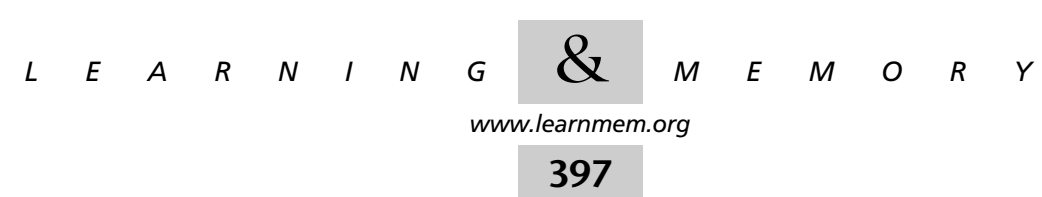


for each of the three groups. Table 1 shows mean startle amplitude data. A one-way ANOVA performed on the percent change scores found a significant effect for group $F(2,21)=3.63, P<.05$. Post hoc Fishers LSD analyses found that the PRD/PRD group showed significant potentiated startle to the odor CS relative to the PRD/UNP and UNP/ PRD groups (all $P$ 's $<.05$ ).

As in Experiment 1, significant second-order conditioning was observed in the PRD/PRD group relative to the controls. However, unlike Experiment 1, the UNP/PRD group did not show significant potentiated startle in the presence of the odor CS.

\section{DISCUSSION}

Significant second-order fear-potentiated startle using olfactory and visual cues was found after only a small number of first and second-order training trials given on separate days. This further attests to the robustness of olfactory fear conditioning, and indicates that these procedures may be especially effective for studying higher-order fear-potentiated startle. The small number of training trials used in the current studies is in contrast to those using CSs of other modalities. For example, to obtain significant second-order potentiated startle using visual and auditory cues, Gewirtz and Davis (1997) had to train animals on different days with four first-order training sessions, three second-order sessions, and then give a fifth first-order session to avoid extinction.

One surprising result in the current studies was the significant potentiated startle to the light CS observed in the Unpaired/Paired (UNP/PRD) group in Experiment 1. Those animals received explicitly unpaired odor-shock presentations in Phase 1 (first-order) conditioning, and paired lightodor presentations in Phase 2 (second-order) conditioning. Previous studies in our lab have shown that animals receiving unpaired odor-shock training showed no potentiated startle to the odor at testing (Paschall and Davis 2002), and therefore, it was predicted that the animals in the UNP/PRD control groups in both second-order studies would not show potentiated startle to the light (Exp. 1), or odor (Exp. 2), at testing. Interestingly, Rizley and Rescorla (1972), using a light as S1 and a tone as S2, reported that their UNP/ PRD group showed significantly more lick suppression to the light than the PRD/UNP group (but significantly less than the PRD/PRD group). They suggested that this result was due to the light itself being a mildly aversive stimulus. It is doubtful that in Experiment 1 there was any unconditioned effects of the light CS on startle amplitude, as the untrained animals in the No/Paired and No/Unpaired groups showed no significant increase in startle in the presence of the light. Further, the animals in the Unpaired/ Unpaired group, which received unpaired odor-shock training in Phase 1 and unpaired light-odor presentations in Phase 2, showed no significant potentiated startle.

One possible explanation for the significant potenti- ated startle to the light in the UNP/PRD group could be that trace conditioning occurred to the odor stimulus in Phase 1 that was sufficient to support second-order conditioning in Phase 2. At first blush this seems unlikely, because as mentioned above, unpaired odor-shock presentations using a 2-min odor-shock interval did not support first-order conditioning when rats were tested subsequently in the presence of the odor (Paschall and Davis 2002). However, it is possible that presentation of an odor paired previously with shock produces not only fear, which would increase startle, but also other behaviors incompatible with startle. For example, we have observed dramatic behavioral effects during strong odor-shock conditioning (e.g., 10 pairings of a 4.0sec odor with a $0.6-\mathrm{mA}$ shock terminating together). Under these training conditions, many rats try vigorously to escape after the first few odor-shock pairings, and will attempt to push their noses through the grid bars into the woodchips below, far away from the odor source. When tested following such intensive training, those animals do not exhibit potentiated startle in the presence of the odor, possibly because active escape behaviors are incompatible with startle (Walker and Davis 1997). When these animals are later retested, they do exhibit significant potentiated startle, which is reminiscent of the non-monotonic relationship between shock intensity in training and level of fear- potentiated startle in testing (Davis and Astrachan 1978). Further, following weaker training, rats do a lot of sniffing when the odor is presented at testing, perhaps also incompatible with startle. Hence, it is possible that trace conditioning using a 2-min odor-shock interval can occur, although its measurement in the presence of the odor is masked by some of these incompatible behaviors.

In second-order conditioning, presentation of the S2 does not seem to elicit a representation of the US, but instead, a representation of the central motivational state elicited by the US (i.e., in this case fear-cf. Gewirtz and Davis 2000) (see also Rescorla 1973; Holland and Rescorla 1975; Holland 1977; Helmstetter and Fanselow 1989). Thus, it is possible that the light, having been paired with the odor in a second-order relationship, produces a state of fear, but not a representation of the odor, and hence, none of the behaviors elicited by the odor that are incompatible with startle (e.g., sniffing). In fact, it is possible that second-order conditioning might be a more sensitive measure of the effects of prior trace conditioning under conditions in which the firstorder stimulus produces behavior incompatible with the behavior under study. Further studies will need to be conducted to examine this trace conditioning hypothesis.

Another possibility is that for the rat, olfactory cues are more readily associated with contexts (i.e., the training chamber) than are visual cues. Marlin (1983) showed that contexts can serve as effective $\mathrm{S} 1$ in second-order conditioning, and suggests that in conventional control procedures used in Pavlovian conditioning (i.e., unpaired CS-US

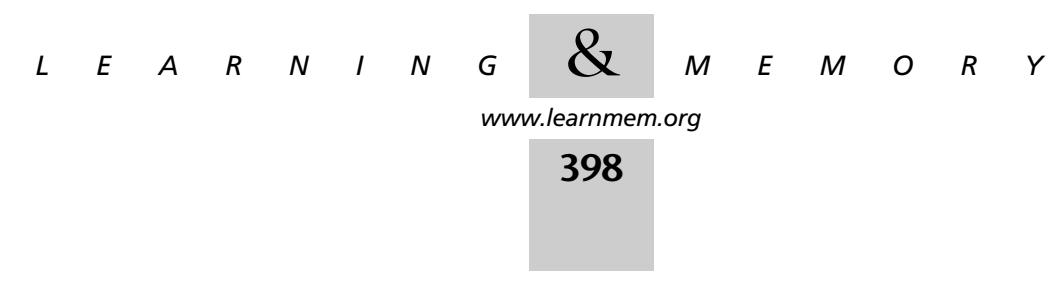


training), any responses observed may be due to secondorder conditioning between the CS and the context. In the UNP/PRD group in Experiment 1, the shock US was delivered in the same context in which the odor CS was presented (in Phase1), and therefore, during the 2-min interstimulus interval, there may have been a greater generalization of fear or anticipation of shock, thus making the context itself excitatory. In Phase 2, the light was paired with the odor in the same, but now excitatory context, which may have enabled conditioning to the light CS to occur. Further studies will need to be conducted to investigate whether second-order olfactory fear conditioning is context specific.

The finding that odors are such robust cues when used in second-order fear conditioning could be very helpful in further delineating the behavioral and neural substrates of fear and anxiety. Because the expression of conditioned fear is dependent upon the amygdala (Campeau and Davis 1995), the anatomical architecture of the olfactory system, with its direct projections to the amygdala that do not involve thalamic relay (unlike the visual or auditory systems), is ideally suited to study the cellular mechanisms of fear and anxiety. Gewirtz and Davis (1997) found that local infusions of the NMDA ( $N$-methyl-D-aspartate) receptor antagonist AP5 (D,L-2-amino-5-phosphonovalerate) into the basolateral amygdala actually enhanced the expression of conditioned fear (i.e., potentiated startle) to S1, but completely blocked the acquisition of second-order fear conditioning using auditory and visual cues. More recently, we found that local infusions of AP5 into the basolateral amygdala blocked the acquisition, but not the expression of olfactory-mediated fear-potentiated startle, whereas infusion of the AMPA/kainate receptor antagonist NBQX (1,2,3,4-Tetrahydro-6-nitro-2,3-dioxo-benzo[f] quinoxaline-7-sulfonamide), blocked both the acquisition and expression of potentiated startle (Paschall et al. 2001). Currently, we are investigating the role of the glutamate transmission within the corticomedial amygdala in olfactory fear conditioning, as this area receives olfactory information directly from both the main and accessory olfactory bulbs.

Second-order olfactory fear conditioning could also be useful in the analysis of gene expression following associative fear conditioning, as investigations of $\mathrm{S} 2$ stimuli would not be confounded by shock-induced gene expression (e.g., Campeau et al. 1991; Rosen et al. 1998). Thus, second-order olfactory fear conditioning could shed light on how seemingly innocuous stimuli become associated with traumatic events, and are then capable of eliciting fear responses in individuals suffering from anxiety disorders such as phobias and PTSD.

\section{MATERIALS AND METHODS}

Methods that were common to all of the current studies are described next. Specific procedures for each individual experiment are described separately.

\section{Subjects}

Experimentally naïe male albino Sprague-Dawley rats obtained from Charles River were used as subjects. The animals weighed $300-400 \mathrm{~g}$ at the start of each behavioral procedure and were housed in groups of four in polypropylene boxes $(45 \times 25 \times 20 \mathrm{~cm})$ at the Emory University animal colony. Animals were maintained on a 12:12 light/dark cycle (lights on at 8:00 am) and had free access to food and water.

\section{Conditioning Apparatus}

In Experiments 1 and 2, all training and testing occurred in two identical stablilimeter cages located within one sound-attenuating chamber (inside dimensions $56 \times 56 \times 81 \mathrm{~cm}$-Industrial Acoustics Corp.). The Industrial Acoustics box was modified so that the top and inner walls were lined with 6.3- $\mathrm{mm}$ Plexiglas. In addition, the fiberglass material in the ventilation unit was removed to avoid absorption of odors. Each stablilimeter consisted of an $8 \times 15 \times$ $15-\mathrm{cm}$ Plexiglas and wire mesh cage suspended between compression springs within a steel frame. The floor of each cage contained four $6.0-\mathrm{mm}$ stainless steel bars spaced $18 \mathrm{~mm}$ apart, through which shock could be delivered. Cage movement produced by a startle response resulted in the displacement of an accelerometer (PCB Piezotronics) affixed to the bottom of each cage. The resultant voltage was proportional to the velocity of the cage displacement. The voltage output of the accelerometer was amplified (PCB Piezotronics, Model 483B21) and digitized on a scale of 0-2500 units by an InstruNet device (GW Instruments, Model 100B) interfaced to a Macintosh G3 computer. Startle amplitude was defined as the maximal peak-to-peak voltage occurring during the first 300 msec after onset of the startle-eliciting stimuli. A surveillance camera (Phillips CCD Camera) was mounted behind each cage and was connected to a TV monitor located outside of the chamber. Two red light bulbs $(7.5 \mathrm{~W})$ were located in the ceiling of the chamber to provide illumination for the cameras.

Background noise $(60 \mathrm{~dB})$ was produced by a white noise generator (ACO Pacific, Inc., Model 3024), and delivered through two high-frequency speakers (Radio Shack Realistic Super Tweeter; Tandy) placed $8 \mathrm{~cm}$ from the front of each cage. Startle responses were evoked by 50-msec, 95-dB white noise bursts generated by the Macintosh G3 computer (0-22 kHz). The noise bursts were amplified by a Radio Shack amplifier (100W; Model MPA-200) and were delivered through the same speakers.

\section{Unconditioned Stimuli}

The unconditioned stimuli were 0.5 -sec footshocks $(0.4 \mathrm{~mA})$ delivered through the floor bars of each cage. Shocks were produced by two LeHigh Valley shock generators (Model SGS-004) located outside of the sound-attenuating chamber. Shock intensity was measured with an oscilloscope across a 101-k resistor connected to adjacent floor bars in each cage. Current was defined as the root mean square voltage across the resistor in which $\mathrm{mA}$ equaled 0.707 $\times 0.5 \times$ peak-to-peak voltage.

\section{Olfactory Apparatus}

This apparatus has been described previously (Paschall and Davis 2002). Briefly, the odor CS was delivered through an olfactometer (Model E15-03-Coulbourne Instruments) mounted outside of the sound-attenuating chamber. It consisted of three solenoid valves with three independent input ports mixing to a common output port. The output was routed into the chamber with PharMed Tygon tubing (3.2 mm ID $\times$ 6.3-mm OD-Norton Plastics, Fisher Scien-

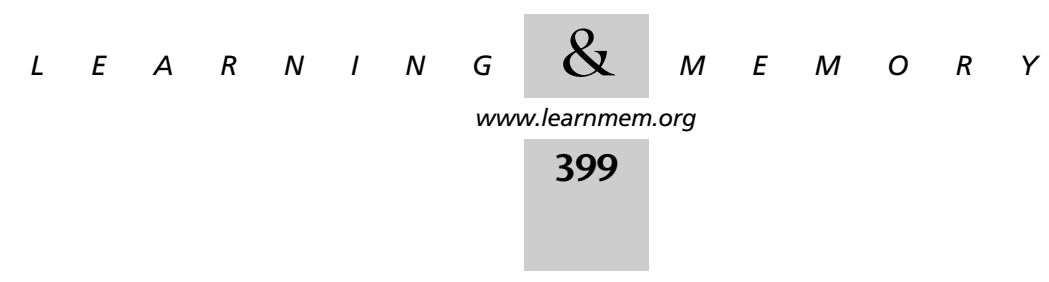


tific). Inside the chamber, the tubing was split with a Y connector and each end was attached to a $15-\mathrm{cm}$ length of tubing that fit tightly onto a tube that protruded through an opening in the top of each cage. To deflect any direct airflow onto the animal's back, a $2.54-\mathrm{cm}$ square metal shield bent in the form of a $\mathrm{V}$ was placed underneath the tube that delivered the airstream.

A compressed air tank (10 psi) was connected to a flowmeter (Fraser Harlake). From the flowmeter, the tubing was split with a $\mathrm{Y}$ connector to two separate check values to prevent backflow. Tubing from each check valve was connected to activated carbon filter devices (Whatman Carbon-Cap 150-Fisher Scientific). Tubing from one filter was attached directly to one of the input ports of the olfactometer (Air solenoid). Tubing from the second filter was fitted with a check valve, and tubing from the valve was attached to a brass inlet connector in the lid of the jar containing $20 \mathrm{~mL}$ of the olfactant (I-CHEM100, 100-mL glass jars with Teflon-lined polypropylene lids-VWR Scientific). The outlet connector in the lid was connected to a second flowmeter, which connected to a second input port of the olfactometer (Odor 1 solenoid). The inlet and outlet connectors were sealed in the lid with $100 \%$ silicone adhesive (Dow Corning) to avoid any leakage.

After the rats were placed in the test cages, the Air solenoid valve was opened to provide a clean airstream continuously during all training and testing sessions at a rate of $2.00 \mathrm{~L} / \mathrm{min}$ to clear the tubing both prior to and after odor presentations. Between individual training/testing sessions, once the animals were removed from the cages, clean air was delivered through the tubing for an additional $5 \mathrm{~min}$ to further clear any residual odor. For the odor cue presentations, the Odor 1 solenoid valve containing the olfactant was opened, the clean air flowrate dropped to $1.25 \mathrm{~L} / \mathrm{min}$, making the final stimulus flow rate $2.00 \mathrm{~L} / \mathrm{min}$. Hence, the introduction of the odor did not lead to any net change in air flow.

A blower fan (McMaster-Carr) provided a continuous influx of clean air into the chamber and an exhaust fan (McMaster-Carr) exhausted air continually from the chamber to minimize any odor lingering between $\mathrm{CS}$ presentations. The fans were vented into and out of the chamber via 3 -inch rubber flex tubing (Home Depot).

Air was exhausted through a $7.62-\mathrm{cm}$ diameter opening at a rate of $10.16 \mathrm{cu} \mathrm{ft} / \mathrm{sec}$ as measured by a Kestrel 1000 wind meter (Nielsen-Kellerman), and the exhausted air was vented outside of the test room. The stabilimeter cages and chamber were cleaned daily following training/testing sessions with warm tap water and 95\% alcohol, and were air dried for at least $8 \mathrm{~h}$.

All stimuli were presented and sequenced under the control of the Macintosh G3 computer using specially designed software (The Experimenter, Glassbeads, Inc.)

\section{Olfactory Stimulus}

The odor-conditioned stimulus (CS) in all experiments was a 4-sec, $5 \%$ solution of amyl acetate (Sigma/Aldrich) diluted in propylene glycol. The odor CS was prepared freshly each day prior to training/ testing sessions.

\section{Visual Stimulus}

The visual-conditioned stimulus was a 4 -sec light produced by an 8-W fluorescent bulb (100- $\mu$ s rise time) located $10 \mathrm{~cm}$ behind each cage. Luminosity was measured using a VWR light meter (VWR Scientific).

\section{Matching Procedure}

In Experiments 1 and 2, on each of two successive days, two animals were placed into two individual test cages within a single startle chamber. Following a 5-min acclimation period, they were presented with 30 startle stimuli $(95 \mathrm{~dB})$ at a $30-\mathrm{sec}$ interstimulus interval (ISI) to determine baseline startle amplitudes. The animals were matched into groups of various sizes ( $n$ 's) depending upon experimental procedure in which each group had equivalent mean startle amplitudes combined over the 30 stimuli.

\section{Statistical Analyses}

The data for all studies were analyzed using the following method: The mean startle amplitude across the 10 CS-Noise trials, (LightNoise trials, Exp. 1; Odor-Noise Trials, Exp. 2) and the 30 NoiseAlone trials (combined over the test trials that came 30,60, and 90 sec later) were computed for each animal. The mean startle amplitude on the collapsed Noise-Alone trials was subtracted from the mean startle amplitude on the CS-Noise trials for each animal (difference scores-see Table 1). Percent change scores for each animal were derived by dividing the difference scores by the NoiseAlone scores. Percent scores were used because they take into account variability in individual animals, and appear to be the best metric of fear-potentiated startle (Walker and Davis 2002). Analysis of variance (ANOVA), and Fishers LSD post hoc analyses were performed using the percent change scores to analyze the data.

\section{ACKNOWLEDGMENTS}

This research was supported by National Institute of Mental Health Grants MH 47840, MH 57250, MH 58922, MH 52384, MH 59906, the Woodruff Foundation, the STC Program, and The Center for Behavioral Neuroscience of the National Science Foundation under Agreement No. IBN-9876754.

The publication costs of this article were defrayed in part by payment of page charges. This article must therefore be hereby marked "advertisement" in accordance with 18 USC section 1734 solely to indicate this fact.

\section{REFERENCES}

Campeau, S. and Davis, M. 1995. Involvement of the central nucleus and basolateral complex of the amygdala in fear conditioning measured with fear-potentiated startle in rats trained concurrently with auditory and visual conditioned stimuli. J. Neurosci. 15: 2301-2311.

Campeau, S., Hayward, M.D., Hope, B.T., Rosen, J.B., Nestler, E.J., and Davis, M. 1991. Induction of the c-fos proto-oncogene in rat amygdala during unconditioned and conditioned fear. Brain Res. 565: 349-352.

Davis, M. and Astrachan, D.I. 1978. Conditioned fear and startle magnitude: Effects of different footshock or backshock intensities used in training. J. Exp. Psychol. Anim. Behav. Process. 4: 95-103.

Domjan, M. 1998. The principles of learning and behavior. 4th ed., pp. 93-94. Brooks/Cole Publishing, Pacific Grove, CA.

Gewirtz, J.C. and Davis, M. 1997. Second-order fear conditioning prevented by blocking NMDA receptors in the amygdala. Nature 388: $471-474$.

- 1998. Application of Pavlovian higher-order conditioning to the analysis of the neural substrates of fear conditioning. Neuropharmacology 37: 453-459.

. 2000. Using Pavlovian "higher-order" conditioning paradigms to investigate the neural substrates of emotional learning and memory. Learn. Mem. 7: 257-266.

Helmstetter, F.J. and Fanselow, M.S. 1989. Differential second-order aversive conditioning using contextual stimuli. Anim. Learn. Behav. 17: 202-212.

Holland, P.C. 1977. Conditioned stimulus as a determinant of the form of the Pavlovian conditioned response. J. Exp. Psychol. Anim. Behav. Process. 3: 77-104.

Holland, P.C. and Rescorla, R.A. 1975. Second-order conditioning with food unconditioned stimulus. J. Comp. Physiol. Psychol. 88: 459-467.

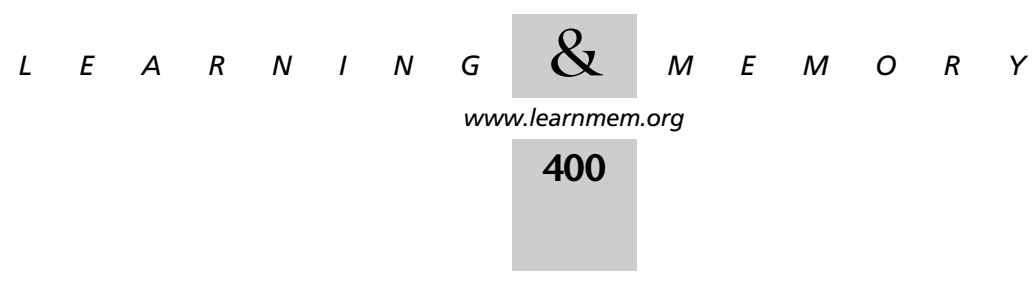


Marlin, N. 1983. Second-order conditioning using a contextual stimulus as S1. Anim. Learn. Behav. 11: 290-294.

Paschall, G.Y. and Davis, M. 2002. Olfactory-mediated fear-potentiated startle. Behav. Neurosci. 116: 4-12.

Paschall, G.Y., Walker, D.L., and Davis, M. 2001. Involvement of glutamate receptors within the amygdala in the acquisition and expression of olfactory-mediated fear-potentiated startle. Soc. Neurosci. Abs. Vol. 27, Program No. 531.10.

Pavlov, I. 1927. Conditioned reflexes Oxford University Press, London, UK.

Rescorla, R.A. 1973. Second-order conditioning: Implications for theories of learning. In Contemporary approaches to conditioning and learning. (eds. F.J. MuGuigan and D.B. Lumdsden), pp. 127-150. V.H. Winston, Washington, D.C.

Rizley, R. and Rescorla, R. 1972. Associations in second-order conditioning and sensory preconditioning. J. Comp. Physiol. Psychol. 81: 1-11.
Richardson, R., Vishney, A., and Lee, J. 1999. Conditioned odor potentiation of startle. Behav. Neurosci. 113: 787-794.

Rosen, J.B., Fanselow, M.S., Young, S.L., Sitcoske, M., and Maren, S. 1998. Immediate-early gene expression in the amygdala following footshock stress and contextual fear conditioning. Brain Res. 796: 132-142.

Walker, D.L. and Davis, M. 1997. Involvement of the dorsal periaqueductal gray in the loss of fear-potentiated startle accompanying high footshock training. Behav. Neurosci. 111: 692-702.

- 2002. Quantifying fear potentiated startle using absolute versus proportional increase scoring methods: Implications for the neurocircuitry of fear and anxiety. Psychopharmacology 159: 304-310.

Received June 3, 2002; accepted in revised form October 2, 2002.

\section{$\begin{array}{lllllllllllllll}L & E & A & R & N & I & N & G & \& & M & E & M & O & R & Y \\ \text { www.learnmem.org } & & & & & & \end{array}$}




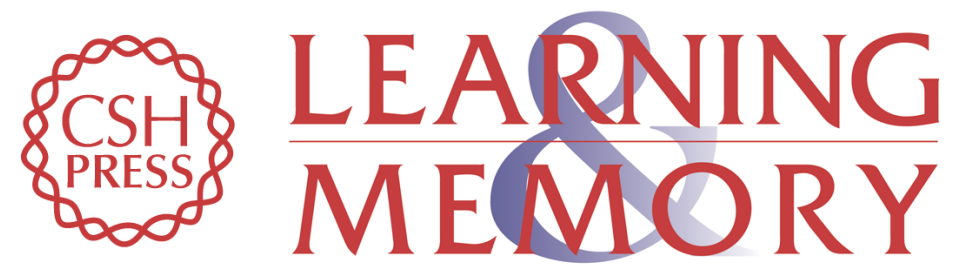

\section{Second-Order Olfactory-Mediated Fear-Potentiated Startle}

Gayla Y. Paschall and Michael Davis

Learn. Mem. 2002, 9:

Access the most recent version at doi:10.1101//m.50602

References This article cites 16 articles, 2 of which can be accessed free at: http://learnmem.cshlp.org/content/9/6/395.full.html\#ref-list-1

License

Email Alerting Service

Receive free email alerts when new articles cite this article - sign up in the box at the top right corner of the article or click here. 